\title{
Transsynaptic connections between the hypothalamus and adipose tissue: relationship to reproduction
}

\author{
K. Czaja \\ Department of Veterinary, Comparative Anatomy, Pharmacology, and Physiology, Washington State \\ University, Pullman, WA 99163-6520, USA
}

Neurophysiological mechanisms that control energy balance are reciprocally linked to those that control reproduction. Neuromorphological studies using retrograde tracing methods revealed that nerve cells within the central (CNS) and autonomic (ANS) nervous systems in different species, including the pig, are transsynaptically connected to different fat tissue depots. In the pig, neurons localised in the paraventricular nucleus, supraoptic nucleus and arcuate nucleus were infected with pseudorabies virus (PRV) 9 days after injections into both the perirenal and subcutaneous adipose tissue depots. Infected neurons were in the ventromedial nucleus, dorsomedial nucleus and preoptic area after injection of PRV into perirenal adipose tissue, while infected cells in the lateral hypothalamic area projected only to the subcutaneous adipose tissue depot. Additionally, numerous centres of the ANS innervate adipose tissue depots in the pig. Fast blue stained $\left(\mathrm{FB}^{+}\right)$neurons, which projected to the subcutaneous adipose tissue overlaying the thoracolumbar area were located in the thoraco-lumbar region of the sympathetic chain ganglia (SChG). However, neurons supplying perirenal and mesentery adipose tissue depots were found in both the SChG and prevertebral ganglia. The vast majority of labelled neurons, in both the CNS and ANS, which innervated adipose tissue depots, expressed leptin receptor (OBR) immunoreactivity. The purpose of this brief review is to establish evidence for a multisynaptic circuit of neurons, which innervate adipose tissue in the pig and demonstrate that hypothalamic nuclei and sympathetic ganglion neurons involved in reproductive processes are transsynaptically connected to different adipose tissue depots.

\section{Introduction}

The physiological mechanisms that control energy balance are reciprocally linked to those that control reproduction (Schneider 2004). Hormones and neuropeptides influence energy balance and reproduction by acting on effector systems in the brain stem and hypothalamus. The central

Address for correspondence: Krzysztof Czaja D.V.M., Ph.D., Department of Veterinary, Comparative Anatomy, Pharmacology, and Physiology, Washington State University, Pullman, WA 99163-6520, USA E-mail: czajak@vetmed.wsu.edu 
effector for control of the hypothalamic-pituitary-gonadal (HPG) system is the network of GnRH neurons located in the anterior hypothalamus, preoptic area (POA) and medial basal hypothalamus $(\mathrm{MBH})$, including the arcuate nucleus (ARC) (Dufourny \& Skinner 2002). The effectors for female sexual behaviour include the ventromedial nucleus (VMN), paraventricular nucleus (PVN), and POA. The effectors for food intake include the areas for control of female sexual behaviour and the lateral hypothalamic area (LHA) and dorsomedial nucleus (Snapir \& Robinzon 1989; Magrani et al., 2004). Metabolic sensory information reaches these hypothalamic areas, which are involved in the HPG system, sex, and feeding behaviour, via the caudal brain stem (Palkovits 2003; Kalra \& Kalra 2004). Hormones can influence central effectors via modulation of metabolic stimuli, or by direct action on neurons in the hypothalamic areas (Schneider 2004).

The purpose of this brief review is to establish evidence for a multisynaptic circuit of neurons, which innervate adipose tissue in the pig and demonstrate that hypothalamic nuclei and sympathetic ganglion neurons involved in reproductive processes are transsynaptically connected to different adipose tissue depots.

\section{Leptin: a link between adipose tissue and the brain}

The role of leptin, which is secreted mainly from adipose tissue and acts at the brain to increase energy expenditure and alter endocrine activity, has been described in many physiological studies (Magni et al., 2000; Barb \& Kraeling 2004). A feedback regulatory loop with three distinct steps has been identified. Leptin production by adipose cells signals the size of the fat tissue mass, and hypothalamic centres receive and integrate the intensity of the leptin signal through leptin receptors and effector systems, including the sympathetic nervous system, thus controlling energy intake and energy expenditure (Schneider 2004). Leptin deficiency in rodents is associated with decreased energy expenditure, impaired thermoregulation, hypercortisol and diabetes (Friedman \& Halaas 1998). Leptin is a potent mediator of metabolic, neuroendocrine and immune responses to fasting (Ahima \& Hileman 2000), and has been implicated in reproduction and glucose and lipid metabolism (Friedman \& Halaas 1998; Schneider 2004). Regulation of energy balance and neuroendocrine function by leptin is thought to be mediated by differential expression of various hypothalamic peptides (Friedman \& Halaas 1998; Barb \& Kraeling 2004). For example, the rise in leptin associated with overfeeding and obesity likely inhibits appetite by decreasing expression of orexigenic peptides (e.g. neuropeptide Y). In contrast, the fall in leptin associated with fasting likely promotes feeding by increasing neuropeptide Y (NPY) and decreasing anorexigenic peptides. Low leptin levels mediate fasting-induced suppression of thyroid and reproductive hormones, and blunt the rise in glucocorticoids, at least in part, by regulating expression of hypophysiotropic peptides, such as TRH, CRH, somatostatin, and GnRH (Ahima \& Hileman 2000; Barb \& Kraeling 2004). While this feedback regulatory loop is well established in rodents, there are many unsolved questions about its applicability to body weight and reproduction in breeding animals. Results from the studies mentioned above provide evidence that leptin is a link between adipose tissue and the brain and indicate the importance of adipose tissue in regulation of energy balance and reproduction. Furthermore, leptin receptors have been found in both the autonomic ganglion neurons and the hypothalamic nuclei involved in reproductive processes and mechanisms that control energy balance (Czaja et al., 2002b; Czaja et al., 2002c; Stepanyan et al., 2003).

\section{Transsynaptic neural tracing in the study of multisynaptic circuits}

Until recently, the anatomical demonstration of the existence of a long, presumably multisynaptic 
pathway, from fat tissue depots to the brain was impossible, because the neuromorphological methods available failed to trace pathways beyond the first synapse. Introduction of the transsynaptic viral tracing technique (Schramm et al., 1993) overcame this problem. Injection of neurotrophic virus into an end-organ infected nerve terminals. The virus travelled from the infected terminals along the axon to the perikaryon where it replicated. The virus then transsynaptically infected neural elements in synaptic contact with the infected perikaryon. From the newly infected terminal, the infection progressed to the second, and in a similar way, to the third- and fourth-order neuron. Infected neurons were visualised with conventional immunohistochemical methods using antibodies against the virus or directly under the fluorescent microscope equipped with the appropriate filter using virus combined with fluorescein. Bartha's $\mathrm{K}$ strain of PRV is one of several viruses frequently used for transsynaptic tracing, and has been widely employed for analysis of multisynaptic circuits following peripheral injections (Card et al., 1993; Jansen et al., 1993). Recent morphological studies using viral tracing revealed that neurons within the CNS are transsynaptically connected to different organs including fat tissue (Bamshad et al., 1999; Song \& Bartness 2001; Czaja et al., 2003; Cano et al., 2004; Zermann et al., 2005). An additional, and important feature of transsynaptic viral tracing is the possibility of performing double immunohistochemical staining, thereby being able to study the phenotypes of infected neurons (Weiss et al., 2001; Czaja et al., 2003).

\section{Hypothalamic and ganglionic projections to adipose tissue in the pig}

Results of our recent studies revealed that PRV-immunoreactive (PRV-IR) neurons are localised in the PVN, supraoptic nucleus (SON) and ARC after injections into both the parakidney (P) and subcutaneous (S) adipose tissue depots overlaying the thoraco-lumbar area in the pig (Fig. 1). PRVIR neurons in the VMN, DMN and POA were present only after injection of PRV into P adipose tissue, while PRV-IR neurons in the LHA projected only to the $S$ adipose tissue depot. These results support the idea of a transsynaptic connection between hypothalamic neurons and different adipose tissue depots in the pig. The general distribution of PRV infected hypothalamic neurons in the pig was similar to that found in the hamster and rat model (Bartness \& Bamshad 1998; Shi \& Bartness 2001; Song \& Bartness 2001), except for specific depot-dependent differences in the distribution and number of PRV-IR neurons. P-specific neurons were located in VMN, DMN and POA while S-specific ones were in the LHA. Two different white adipose tissue depots were previously studied in the Siberian hamster. There were no statistically significant differences in the pattern of labelled cells after inguinal or epididymal adipose tissue virus injections. Greater differences between brown (BAT) and white adipose tissue (WAT) depots were reported by Bamshad et al. (1999) and Shi and Bartness (2001). The WAT received innervation from the POA, PVN, LHA, dorsal hypothalamic area (DHA), DMN, and posterior hypothalamic nucleus (PHN). The BAT, in turn, was supplied by neurons originating from the VMN, ARC, PVN, suprachiasmatic nucleus $(\mathrm{SCN}), \mathrm{LHA}, \mathrm{POA}$, bed nucleus of the stria terminals (BNST) and lateral septum (LS). The number of infected neurons in our study differed from the previous studies. Furthermore, there were differences in number of infected neurons between $\mathrm{P}$ and $\mathrm{S}$ subpopulations. The differences mentioned above may have resulted from different titers and volumes of PRV used as well as mass and topography of the adipose tissue depots (Bartness \& Bamshad 1998; Bamshad et al., 1999; Shi \& Bartness 2001; Song and Bartness 2001; Czaja et al., 2003). The difference in total number of PRVIR neurons in the $\mathrm{P}$ and $\mathrm{S}$ depots, with respect to the volume of particular fat tissue depot, indicates a denser innervation of $\mathrm{P}$ than of $\mathrm{S}$ adipose tissue. However, more detailed morphometric neuroanatomical studies are needed to support this hypothesis.

It was previously reported that autonomic ganglion neurons project to adipose tissue in the 


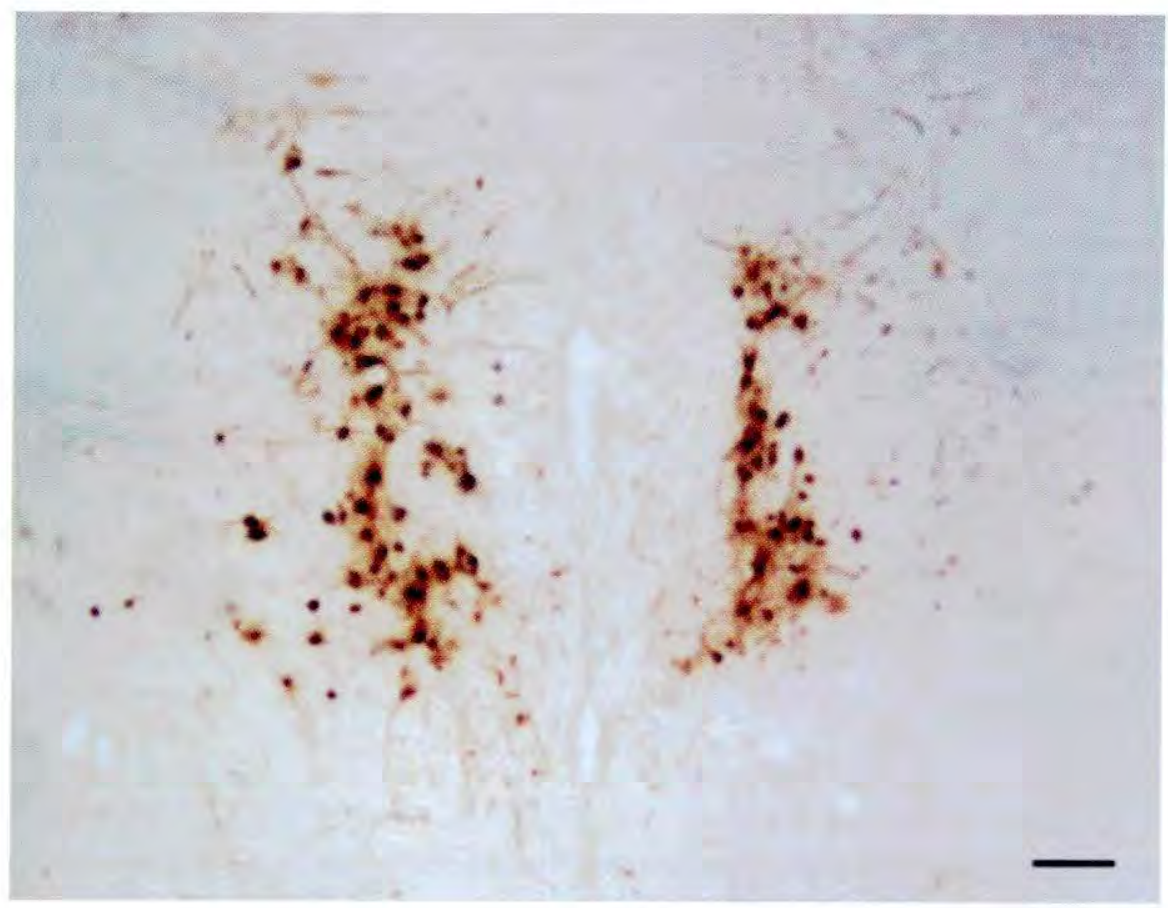

Fig. $1 \mathrm{Imm}$ mohistochemistry with primary antibody against PRV. Diaminobenzidine (DAB) stained neurons located in the PVN innervate subcutaneous (S) adipose tissue. Scale Bar $=100 \mu \mathrm{m}$.

pig (Czaja et al., 2002a). Retrograde labelled $\mathrm{FB}^{+}$neurons, which innervate $\mathrm{S}$ adipose tissue were found in the ipsilateral thoraco-lumbar $\left(\mathrm{Th}_{1}-\mathrm{L}_{4}\right)$ ganglia of the sympathetic chain. Neurons supplying the perirenal adipose tissue depot were located in the celiac superior mesenteric (CSMG), ipsilateral adrenal (ADG), aortico-renal (ARG), ovarian (OG) and inferior mesenteric (IMG) ganglia, as well as in the ipsilateral lumbar sympathetic chain ganglia (SChG) at the level of $\mathrm{L}_{1}-\mathrm{L}_{3}$, whereas $\mathrm{FB}^{+}$neurons innervating mesenteric adipose tissue were localised in the CSMG and both the right and left ADG, ARG, OG and IMG, as well as in the right thoracolumbar SChG at the level of $\mathrm{Th}_{13}-\mathrm{L}_{3}$. These differences may result from different topographies and extent of the adipose tissue depots. Previous experiments carried out by means of the retrograde tracing method in the pig (Majewski et al., 1995; Wasowicz et al., 1998; Czaja et al., 2001) showed organ-related differences in the distribution of neurons supplying the genital organs. Differences in the distribution of neurons innervating the oviduct, ovary and uterus may be a result of the different pathways used by the axons of those neurons to reach the target tissues. This hypothesis may also explain differences in localization of the sympathetic nerve sources supplying subcutaneous, perirenal and mesentery fat depots in the pig.

\section{Hypothalamic nuclei projecting to porcine adipose tissue: relationship to reproduction, energy balance and feeding behaviour}

Neuronal tracing studies showed that, irrespective of the species and the tissue depot, numerous subpopulations of neurons in the PVN innervate adipose tissue in both laboratory animals and the pig (Bamshad et al., 1999; Shi \& Bartness 2001; Czaja et al., 2003). The PVN provides 
some inputs to most other hypothalamic areas, including the DMN, VMN, ARC, anterior hypothalamus, and perifornical area in the LHA. However, the most recognised outputs from the PVN are magnocellular secretory neurons, which project to the posterior pituitary and secrete oxytocin and vasopressin, and the parvicellular secretory neurons, which produce $\mathrm{CRH}$ and $\mathrm{TRH}$, thereby stimulating secretion of glucocorticoids from the adrenal cortex and thyroid hormone from the thyroid gland (Luiten et al., 1987). With respect to feeding behaviour, the PVN organises appropriate endocrine and autonomic responses by integrating information, such as gastrointestinal fill and availability of substrates and metabolites with information from adipose stores. It does not have a direct role in food intake, but an indirect one via changes in digestive, absorptive and metabolic processes, and it plays a role in stress-induced changes in food intake (Berthoud 2002). Numerous subpopulations of hypothalamic neurons, which project to adipose tissue, are also located in the POA in laboratory animals, while in the pig, these subpopulations were located in the SON and ARC (Czaja et al.; unpublished data). The role of the POA in food intake and reproduction by way of oestrogen receptors was previously described in laboratory animals (Mascarenhas 1986; Alexander \& Leeman 1992). In the pig, infected neurons were present in the POA only after injection of PRV into the P fat tissue depot and represented the smallest subpopulation of labelled neurons. These results in the pig are in contrast to those obtained from laboratory animals, which demonstrated that SON and ARC neurons supplying adipose tissue is one of the smallest subpopulations ( Bartness \& Bamshad 1998; Bamshad et al., 1999; Shi \& Bartness 2001; Song \& Bartness 2001). The SON is generally believed to consist principally of neurons that synthesise oxytocin and vasopressin. While vasopressin is predominantly involved in regulation of osmotic balance, oxytocin plays important roles in reproductive processes by way of receptors localised on PVN and SON neurons (Higuchi \& Okere 2002; Popeski et al., 2003). The ARC nucleus is part of the neuronal system, which regulates food intake and body weight (Schwartz et al., 1999) as well as reproduction (Krasnow et al., 2003; Cunningham et al., 2004; Kageyama et al., 2005). The medial part of the ARC participates in induction of feeding, particularly by activation of neurons producing NPY (Wang et al., 2002). The smallest subpopulations of neurons innervating porcine $P$ and/or $S$ adipose tissue were found in the VMN, DMN, POA and LHA. In the pig, infected neurons were found in the VMN, DMN and POA only after injection of PRV into P adipose tissue, while infected cells in the LHA projected only to the S adipose tissue depot, suggesting that there are depot-dependent differences in innervation of adipose tissue at the level of the CNS. Such differences were previously reported in the pig ANS (Czaja et al., 2002a). These findings support the concept of depot-dependent functions and regional differences in metabolism of adipose tissue (Montague et al., 1997; Arner 2001).

Double-labelling immunofluorescence demonstrated that leptin receptor (OBR) co-localised in almost all virus-infected hypothalamic neurons supplying porcine adipose tissue (Fig. 2). The presence of OBR on neurons, which are localised in the hypothalamus, and innervate adipose tissue, was previously reported in both laboratory animals and the pig (Oldfield et al., 2002; Czaja et al., 2003). Numerous immunohistochemical and physiological studies revealed that projections of OBR-IR neurons provide a link between the hypothalamus and other brain regions involved in satiety and reproductive functions (Magni et al., 2000; Barb et al., 2001; Lin et al., 2001; Czaja et al., 2002c). These findings suggest that leptin not only plays an integrative role in feeding behaviour, but also in neuroendocrine activity. The importance of leptin in feeding behaviour has been reported in different species (Hunter et al., 2004; Matochik et al., 2005). However, leptin's influence on reproductive function still remains open to discussion. Recent studies revealed different populations of leptin-target cells, including GnRH neurons and others, in different regions of the hypothalamus. GnRH neurons express leptin receptors in different species (Barb et al., 2004; Barb \& Kraeling 2004; Thomas et al., 2004; Amstalden et 
A

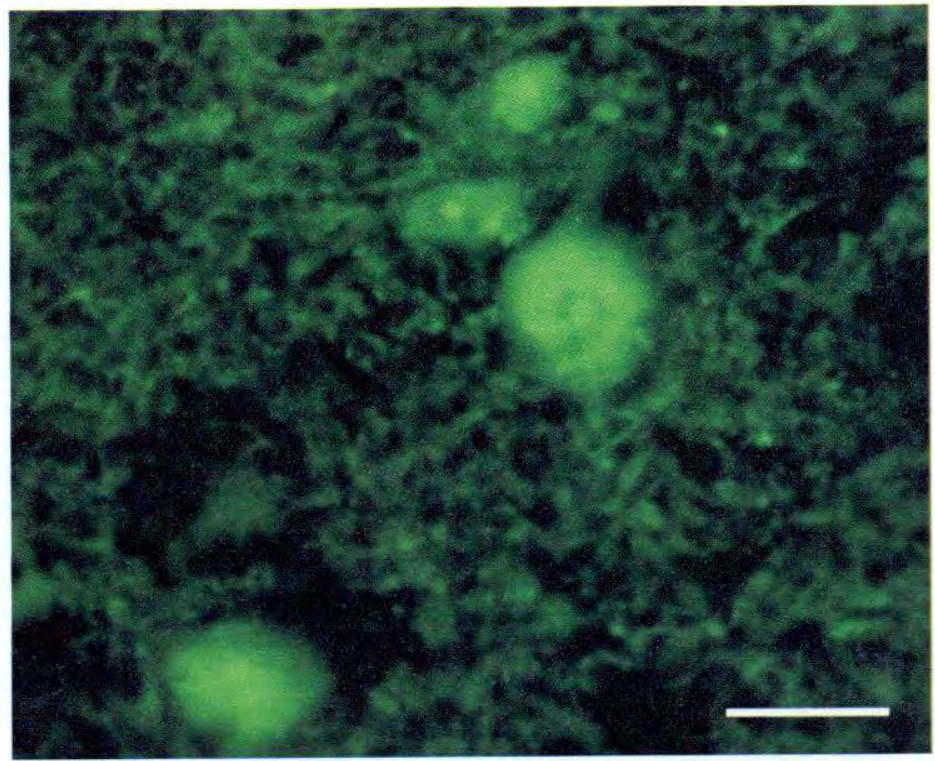

B

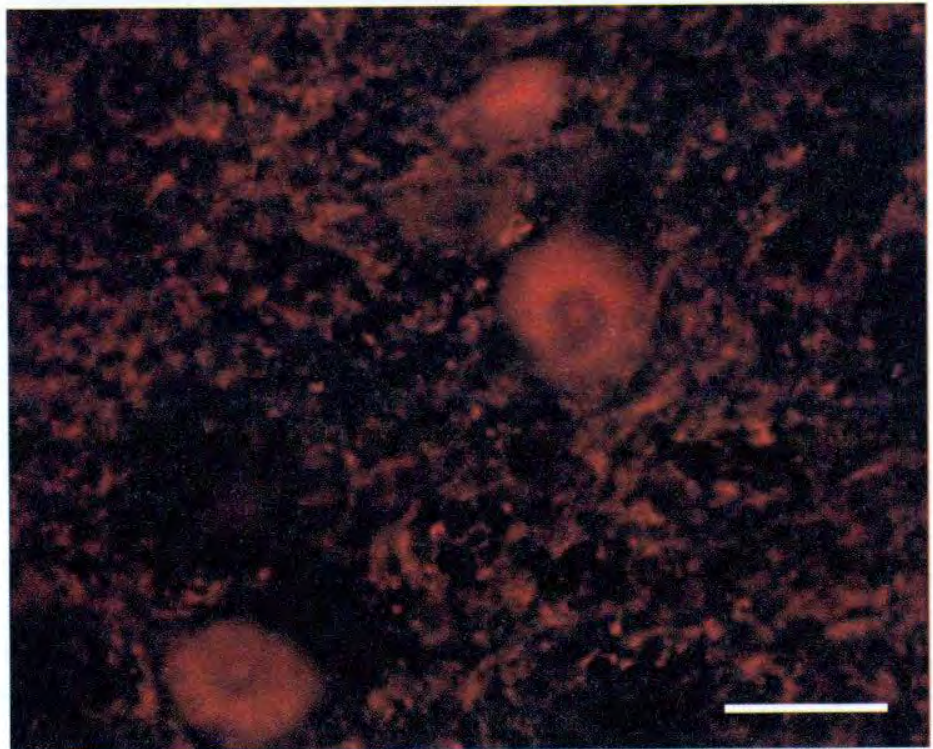

Fig. 2 Double-labelling immunofluorescence. Group of four PRV-IR neurons located in PVN, which project to perirenal (P) adipose tissue (Fig. 2a). Three of them simultaneously expressed OBR-immunoreactivity (Fig. 2b). Scale Bar $=20 \mu \mathrm{m}$.

al., 2005), therefore, it is possible that a subpopulation of $\mathrm{GnRH}$ neurons, which express leptin receptors, may mediate actions of leptin on gonadotropin secretion. A variety of ARC neurons, which synthesise/release NPY and POMC are thought to interact with GnRH neurons and are candidates for mediating the effects of leptin on reproduction. Neuropeptide $Y$ influences GnRH and LH secretion in rats and other species (Kalra \& Kalra 1996), and ARC neuropeptide $Y$ neurons express OBR. Similarly, many hypothalamic POMC neurons express leptin receptors (Funahashi et al., 2003; Balthasar et al., 2004). POMC neurons make direct synaptic contacts 
with GnRH neurons (Leranth et al., 1988) and peptide products of the POMC precursor are possible mediators of leptin action (Kalra \& Kalra 1996). There are several other mechanisms by which leptin could affect reproductive function, including effects on the hypothalamo-pituitary-adrenal axis, namely secretion of $\mathrm{CRH}$ and/or glucocorticoids (Barb \& Kraeling 2004), which in turn, affect $\mathrm{LH}$ secretion.

\section{Summary and conclusion}

Evidence was presented, which strongly supports the concept of direct connections between neural regulatory circuits controlling feeding behaviour and reproductive functions. A hypothalamic regulatory network comprising a neural axis linking the ARC to the PVN, with additional communication via the neighboring lateral hypothalamus and ventromedial hypothalamus, together integrate responses to and from peripheral visceral organs involved in energy balance and reproduction (Berthoud 2002; Palkovits 2003; Barb \& Kraeling 2004; Kalra \& Kalra 2004; Schneider 2004). Additional research is needed to develop a complete understanding of the adipose tissue-brain-pituitary axis, which will lead to practical methods of controlling appetite, metabolism and reproduction. Double-labelled transsynaptic tracing from both the adipose tissue and the reproductive organs performed in the same animal may generate more detailed and direct neuroanatomical data supporting the hypothesis that feeding and reproduction neural circuits overlap.

\section{Acknowledgements}

Appreciation is extended to Dr. P.J. Fedorka-Cray and Dr. C. K. Song for expert and essential technical assistance. This research was supported jointly by NATO Science Fellowships and USDA Foreign Currency Research Program.

\section{References}

Ahima RS, Hileman SM (2000) Postnatal regulation of hypothalamic neuropeptide expression by leptin: implications for energy balance and body weight regulation. Regul.Pept. 92, 1-7.

Alexander MJ, Leeman SE (1992) Neurotensin gene expression in the rat preoptic area. Implications for the regulation of reproduction. Ann.N.Y.Acad.Sci. 668, 70-89.

Amstalden M, Harms PG, Welsh TH, Jr., Randel RD, Williams CL. (2005) Effects of leptin on gonadotropin-releasing hormone release from hypothalamicinfundibular explants and gonadotropin release from adenohypophyseal primary cell cultures: further evidence that fully nourished cattle are resistant to leptin. Anim Reprod.Sci. 85, 41-52.

Arner P (2001) Regional differences in protein production by human adipose tissue. Biochem.Soc.Trans. 29, 72-75.

Balthasar N, Coppari R, McMinn J, Liu SM, Lee CE, Tang V, Kenny CD, McGovern RA, Chua SC, Ir., Elmquist JK, Lowell BB (2004) Leptin receptor signaling in POMC neurons is required for normal body weight homeostasis. Neuron 42, 983-991.
Bamshad M, Song CK, Bartness TJ (1999) CNS origins of the sympathetic nervous system outflow to brown adipose tissue. Am.J.Physiol 276, R1569-R1578.

Barb CR, Barrett JB, Kraeling RR (2004) Role of leptin in modulating the hypothalamic-pituitary axis and luteinizing hormone secretion in the prepuberal gilt. Domest.Anim Endocrinol. 26, 201-214.

Barb CR, Kraeling RR (2004) Role of leptin in the regulation of gonadotropin secretion in farm animals. Anim Reprod.Sci. 82-83, 155-167.

Barb CR, Kraeling RR, Rampacek GB (2001) Nutritional regulators of the hypothalamic-pituitary axis in pigs. Reprod.Suppl 58, 1-15.

Bartness TJ, Bamshad M (1998) Innervation of mammalian white adipose tissue: implications for the regulation of total body fat. Am.J.Physiol 275, R1399-R1411.

Berthoud HR (2002) Multiple neural systems controlling food intake and body weight. Neurosci.Biobehav.Rev. 26, 393-428.

Cano G, Card JP, Sved AF (2004) Dual viral transneuronal tracing of central autonomic circuits involved in the innervation of the two kidneys in rat. J.Comp Neurol. 471, $462-481$. 
Card JP, Rinaman L, Lynn RB, Lee BH, Meade RP, Miselis RR, Enquist LW (1993) Pseudorabies virus infection of the rat central nervous system: ultrastructural characterization of viral replication, transport, and pathogenesis. J.Neurosci. 13, 2515-2539.

Cunningham MJ, Shahab M, Grove KL, Scarlett JM, Plant TM, Cameron JL, Smith MS, Clifton DK, Steiner RA (2004) Galanin-like peptide as a possible link between metabolism and reproduction in the macaque. J.Clin.Endocrinol.Metab 89, 1760-1766.

Czaja K, Kaleczyc I, Pidsudko Z, Franke-Radowiecka A, Lakomy $M$ (2001) Distribution of efferent neurones innervating the oviduct in the pig. Folia Morphol. (Wars. ) 60, 243-248.

Czaja K, Kraeling R, Klimczuk M, Franke-Radowiecka A, Sienkiewicz W, Lakomy M (2002a) Distribution of ganglionic sympathetic neurons supplying the subcutaneous, perirenal and mesentery fat tissue depots in the pig. Acta Neurobiol.Exp.(Wars.) 62, 227-234.

Czaja K, Kraeling RR, Barb CR (2003) Are hypothalamic neurons transsynaptically connected to porcine adipose tissue? Biochem.Biophys.Res.Commun. 311, 482-485.

Czaja K, Lakomy M, Kaleczyc J, Barb CR, Rampacek CB, Kraeling RR (2002b) Leptin receptors, NPY, and ryrosine hydroxylase in autonomic neurons supplying fat depots in a pig. Biochem.Biophys.Res.Commun. 293, $1138-1144$.

Czaja K, Lakomy M, Sienkiewicz W, Kaleczyc J, Pidsudko Z, Barb CR, Rampacek GB, Kraeling RR (2002c) Distribution of neurons containing leptin receptors in the hypothalamus of the pig. Biochem.Biophys.Res.Commun. 298, 333-337.

Dufourny L, Skinner DC (2002) Type II glucocorticoid receptors in the ovine hypothalamus: distribution, influence of estrogen and absence of co-localization with GnRH. Brain Res. 946, 79-86.

Friedman JM, Halaas JL (1998) Leptin and the regulation of body weight in mammals. Nature 395, 763770.

Funahashi H, Yamada S, Kageyama H, Takenoya F, Guan JL, Shioda S (2003) Co-existence of leptin- and orexinreceptors in feeding-regulating neurons in the hypothalamic arcuate nucleus-a triple labeling study. Peptides 24, 687-694.

Higuchi T, Okere CO (2002) Role of the supraoptic nucleus in regulation of parturition and milk ejection revisited. Microsc. Res.Tech. 56, 113-121.

Hunter RG, Philpot K, Vicentic A, Dominguez G, Hubert GW, Kuhar MJ (2004) CART in feeding and obesity. Trends Endocrinol.Metab 15, 454-459.

Jansen AS, Farwell DG, Loewy AD (1993) Specificity of pseudorabies virus as a retrograde marker of sympathetic preganglionic neurons: implications for transneuronal labeling studies. Brain Res. 617, 103112.

Kageyama H, Takenoya F, Kita T, Hori T, Guan JL, Shioda $S$ (2005) Galanin-like peptide in the brain: effects on feeding, energy metabolism and reproduction. Regul.Pept. 126, 21-26.

Kalra SP, Kalra PS (1996) Nutritional infertility: the role of the interconnected hypothalamic neuropeptide Y-galanin-opioid network. Front Neuroendocrinol. 17, 371-401.

Kalra SP, Kalra PS (2004) Overlapping and interactive pathways regulating appetite and craving. J.Addict.Dis. 23, 5-21.

Krasnow SM, Fraley GS, Schuh SM, Baumgartner JW, Clifton DK, Steiner RA (2003) A role for galanin-like peptide in the integration of feeding, body weight regulation, and reproduction in the mouse. Endocrinology 144, 813-822.

Leranth C, MacLusky NJ, Shanabrough M, Naftolin F (1988) Immunohistochemical evidence for synaptic connections between pro-opiomelanocortin-immunoreactive axons and LH-RH neurons in the preoplic area of the rat. Brain Res. 449, 167-176.

Lin J, Richard BC, Kraeling RR, Rampacek GB (2001) Developmental changes in the long form leptin receptor and related neuropeptide gene expression in the pig brain. Biol.Reprod. 64, 1614-1618.

Luiten PG, Ter Horst GJ, Steffens AB (1987) The hypothalamus, intrinsic connections and outflow pathways to the endocrine system in relation to the control of feeding and metabolism. Prog.Neurobiol. 28, 1-54.

Magni P, Motta M, Martini L (2000) Leptin: a possible link between food intake, energy expenditure, and reproductive function. Regul.Pept. 92, 51-56.

Magrani I, de Castro e Silva, Varjao B, Duarte G, Ramos AC, Athanazio R, Barbetta $M$, Luz P, Fregoneze 18 (2004) Histaminergic $H 1$ and $H 2$ receptors located within the ventromedial hypothalamus regulate food and water intake in rats. Pharmacol.Biochem.Behav. 79, $189-198$.

Majewski M, Sienkiewicz W, Kaleczyc J, Mayer B, Czaja K, Lakomy $M$ (1995) The distribution and co-localization of immunoreactivity to nitric oxide synthase, vasoactive intestinal polypeptide and substance $P$ within nerve fibres supplying bovine and porcine female genital organs. Cell. Tissue Res. 281, 445 464.

Mascarenhas JF (1986) Role of medial preoptic area (MPOA) in the reproductive function and feeding behavior in rats. Indian J.Physiol Pharmacol. 30, 232240.

Matochik JA, London ED, Yildiz BO, Ozata M, Caglayan S, Depaoli AM, Wong ML, Licinio / (2005) Effect of leptin replacement on brain structure in genetically leptin-deficient adults. J.Clin.Endocrinol.Metab.

Montague CT, Prins JB, Sanders L, Digby JE, O'Rahilly S (1997) Depot- and sex-specific differences in human leptin mRNA expression: implications for the control of regional fat distribution. Diabetes $46,342-$ 347.

Oldfield BJ, Giles ME, Watson A, Anderson C, Colvill LM, McKinley MJ (2002) The neurochemical characterisation of hypothalamic pathways projecting polysynaptically to brown adipose tissue in the rat. Neuroscience 110, 515-526.

Palkovits M (2003) Hypothalamic regulation of food intake. Ideggyogy.Sz 56, 288-302.

Popeski N, Amir S, Diorio J, Woodside B (2003) Prolac- 
tin and oxytocin interaction in the paraventricular and supraoptic nuclei: effects on oxytocin mRNA and nitric oxide synthase. J.Neuroendocrinol. 15, 687-696.

Schneider JE (2004) Energy balance and reproduction. Physiol Behav. 81, 289-317.

Schramm LP, Strack AM, Platt KB, Loewy AD (1993) Peripheral and central pathways regulating the kidney: a study using pseudorabies virus. Brain Res. 616, 251-262.

Schwartz MW, Baskin DG, Kaiyala KJ, Woods SC (1999) Model for the regulation of energy balance and adiposity by the central nervous system. Am.J.Clin. Nutr. 69, 584-596.

Shi H, Bartness TJ (2001) Neurochemical phenotype of sympathetic nervous system outflow from brain to white fat. Brain Res.Bull. 54, 375-385.

Snapir N, Robinzon B (1989) Role of the basomedial hypothalamus in regulation of adiposity, food intake, and reproductive traits in the domestic fowl. Poult.Sci. 68, 948-957.

Song CK, Bartness TJ (2001) CNS sympathetic outflow neurons to white fat that express $M E L$ receptors may mediate seasonal adiposity. Am.J.Physiol Regul.Integr.Comp Physiol 281, R666-R672.
Stepanyan Z, Kocharyan A, Pyrski M, Hubschle T, Watson AM, Schulz S, Meyerhof W (2003) Leptin-target neurones of the rat hypothalamus express somatosta. tin receptors. J.Neuroendocrinol. 15, 822-830.

Thomas AD, Murray JD, Oberbauer AM (2004) Leptin modulates fertility under the influence of elevated growth hormone as modeled in oMt1a-oGH transgenic mice. J.Endocrinol. 182, 421-432.

Wang H, Storlien LH, Huang XF (2002) Effects of dietary fat types on body fatness, leptin, and ARC leptin receptor, NPY, and AgRP mRNA expression. Am.J.Physiol. Endocrinol.Metab. 282, E1352-E1359.

Wasowicz K, Majewski M, Lakomy M (1998) Distribution of neurons innervating the uterus in the pig. J. Auton. Nerv. Syst. 74, 13-22.

Weiss ML, Chowdhury SI, Patel KP, Kenney MJ, Huang J (2001) Neural circuitry of the kidney: NO-containing neurons. Brain Res. 919, 269-282.

Zermann DH, Ishigooka $M$, Doggweiler-Wiygul R, Schubert J, Schmidt RA (2005) Central autonomic innervation of the kidney. What can we learn from a transneuronal tracing study in an animal model? J.Urol. 173, 1033-1038. 